\title{
Assessment of Total Occlusal Convergence for Crown Preparation: A Comparative Study
}

\author{
Sultan A Almalki ${ }^{1}$, Khulud A Al-Aali ${ }^{2}$, Abdulaziz A AlHelal ${ }^{3}$, Roaa Y Hejazi ${ }^{4}$, Haifa M Abuhaimed ${ }^{5}$
}

\begin{abstract}
Aim: The aim of the study was to assess the total occlusal convergence guessing by sight and ruler methods and compare with the snapshots for accuracy.

Materials and methods: The methods used for total occlusal convergence (TOC) preparation were assessed among students, interns, and dental specialists after die preparation and compared with the snapshots for accuracy.

Results: In all, $47 \%$ of the specialist's observation achieved the recommended TOC angle, while $29.25 \%$ was obtained by undergraduates.

Conclusion: In conclusion, specialist's observation was better in both ruler and sight guessing methods compared to dental students and interns. Clinical significance: The abutment for dental prosthesis should have a minimal TOC, also called a taper, for adequate retention of the abutment. Keywords: Microscopes, Sight method, Taper, Total occlusal convergence.

World Journal of Dentistry (2020): 10.5005/jp-journals-10015-1711
\end{abstract}

\section{INTRODUCTION}

Complete crown coverage is highly recommended for badly destructed and endodontically treated teeth. ${ }^{1}$ Several factors play important roles in retention and resistance of the crown, such as height of the prepared tooth, type of dental cement, and convergence angle of tooth preparation. ${ }^{2-8}$

The features that prevent dislodgment of a crown along its path of insertion is called retention, e.g., forces acting along the long axis of the tooth. The features that prevent crown dislodgment when oblique (nonaxial) forces act on the tooth called resistance. ${ }^{9}$

The total occlusal convergence (TOC) angle of a tooth preparation is the combined angle made by opposing axial walls when measured against the vertical long axis of the tooth. ${ }^{5}$ Greater retention occurs when we have more nearly parallel opposing walls of a preparation. ${ }^{10,11}$

The ideal taper recommended by fixed prosthodontics textbooks and different dental schools is $2^{\circ}$ to $7^{\circ}$ per axial wall or $4^{\circ}$ to $14^{\circ}$ total TOC. ${ }^{2}$ Based on a systematic review by Goodacre et al. in 2001, a clinically accepted TOC is $10^{\circ}$ to $20^{\circ} .9$

However, in real-life situations, idealistic preparations in oral cavity with no undercuts are not always achievable. Many techniques have been described to evaluate the TOC angle of tooth preparation using devices such as photocopy machines, three-dimensional laser scanners, and overhead projectors, ${ }^{12-14}$ but none of these devices can be available during clinical evaluation of a tooth preparation in clinical setting, in addition many specialists been evaluating their preparation by guessing by sight and sometimes computer-aided design/computer-aided manufacturing (CAD/CAM) software can give them an idea after sending their impression to fabrication.

The convergence angle method definitely influences crown retention. Therefore, it is essential that dental students become competent in achieving acceptable abutment taper. Theoretically, the more parallel the opposing walls of a tooth preparation are, the greater the retention and the more conservative is the tooth preparation. It is widely accepted that the convergence angle of
${ }^{1}$ Department of Preventive Dental Sciences, College of Dentistry, Prince Sattam Bin AbdulAziz University, Alkharj, Kingdom of Saudi Arabia

${ }^{2}$ Department of Clinical Dental Sciences, College of Dentistry, Princess Nourah Bint Abdulrahman University, Riyadh, Kingdom of Saudi Arabia ${ }^{3}$ Department of Prosthetic Dental Sciences, College of Dentistry, King Saud University, Riyadh, Kingdom of Saudi Arabia

${ }^{4,5}$ College of Dentistry, Princess Nourah Bint Abdulrahman University, Riyadh, Kingdom of Saudi Arabia

Corresponding Author: Sultan A Almalki, Department of Preventive Dental Sciences, College of Dentistry, Prince Sattam Bin AbdulAziz University, Alkharj, Kingdom of Saudi Arabia, Phone: +966557611000, e-mail: s.almalki@psau.edu.sa

How to cite this article: Almalki SA, Al-Aali KA, AlHelal AA, et al Assessment of Total Occlusal Convergence for Crown Preparation: A Comparative Study. World J Dent 2020;11(1):61-64.

Source of support: Nil

Conflict of interest: None

a full-veneer crown preparation should be as close to parallel as possible to attain adequate retention and resistance.

The main aim of the present study was to compare the overall value of TOC of crown preparation in Princess Nourah Bint Abdulrahman University between dental students, interns, and specialist prosthodontists using guessing by sight and ruler methods, and these were compared with snapshots for accuracy.

\section{Materials and Methods}

A cross-sectional study was conducted to assess and measure the total convergence angle of tooth preparation for complete crowns done by Princess Nourah Bint Abdulrahman University undergraduate students and specialist prosthodontists at College of Dentistry, Princess Nourah Bint Abdulrahman University, utilizing

() The Author(s). 2020 Open Access This article is distributed under the terms of the Creative Commons Attribution 4.0 International License (https://creativecommons. org/licenses/by-nc/4.0/), which permits unrestricted use, distribution, and non-commercial reproduction in any medium, provided you give appropriate credit to the original author(s) and the source, provide a link to the Creative Commons license, and indicate if changes were made. The Creative Commons Public Domain Dedication waiver (http://creativecommons.org/publicdomain/zero/1.0/) applies to the data made available in this article, unless otherwise stated. 
the different methods; guessing by sight, the manual convergence angle ruler (TOC Ruler) and compared with digital snapshots.

\section{Study Subjects}

Tooth preparation dies for single-teeth abutments were collected from undergraduate students in Princesses Norah Bint Abdulrahman University dental clinic. A total of 30 participated in the study, i.e., 10 students, 10 interns, and 10 specialists.

\section{Selection Criteria}

Samples were included based on the following inclusion and exclusion criteria:

\section{Inclusion Criteria}

(1) Dies of successfully delivered complete crown to the patient; (2) no instructions were given to the operator; and (3) tooth preparations were done by undergraduate students and specialist prosthodontists (SPs) in PNU-DC.

\section{Exclusion Criteria}

Anterior teeth were excluded from the study because of the deficiency in the numbers of mandibular anterior teeth.

\section{Procedure}

After distribution of posterior crown to the patients, 10 dies each were collected from Princess Nourah Bint Abdulrahman University Dental Lab as follows.

- 10 students,

- 10 interns, and

- 10 specialists.

Each die was labeled prior to measurement and reading. The 10 dies received readings from undergraduate students and specialist prosthodontists using different measurement methods (Flowchart 1).

Guessing by sight method ensures visually guessing the tapered angle of the prepared tooth. And manual convergence angle ruler method was a combined angle made by opposing axial walls when measured against the long axis of the tooth. Taper was the angle between one axial wall of the preparation and the long axis of the preparation (Fig. 1). Each group's participants made 100 reading (each participants made 10 readings) for guessing by sight and 100 reading (each participants made 10 readings) for the manual

Flowchart 1: Dies readings from students, interns, and specialists

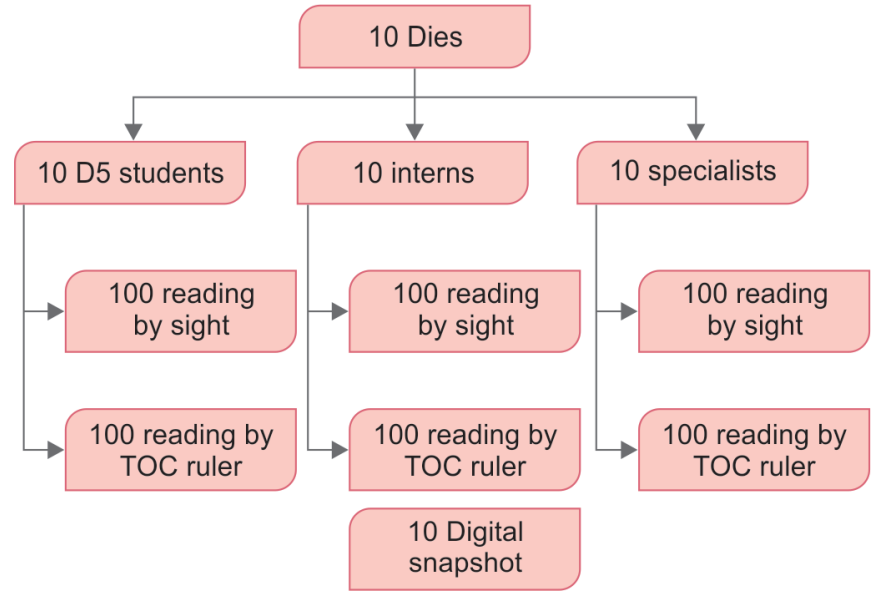

convergence angle ruler (TOC Ruler) for all the 10 dies. Then the 10 digital snapshots were taken to measure both the buccolingual (BL) TOC and mesiodistal (MD) TOC. These cross sections were later imported to software where tangents were drawn, from which the angles were measured. Tangents were drawn out and measured on each axial surface of the tooth (mesial, distal, buccal, and lingual) for a smaller margin of error. The measurements of snapshot TOC were performed by a single investigator to avoid the risk of differences in measurement between observers for all the 10 dies, and data were compared using statistical software. A total of 610 readings were achieved by the end of the study.

\section{Results}

The results for TOC comparisons between three main groups, namely, dental students, interns, and SP using two different methods of assessment (by guessing and TOC Ruler) are shown in Table 1.

About $49 \%$ of the interns along with $31 \%$ of the students achieved the recommended TOC angle $\left(10^{\circ}\right.$ to $\left.20^{\circ}\right)$ for the respective MD surface by sight method, while $28 \%$ of the interns and $33 \%$ of the students obtained it by ruler method.

For BL surface, $59 \%$ of the interns have achieved it by sight and $26 \%$ by ruler method. In comparison, for the MD surface, the reading was done by specialists; about $49 \%$ achieved the recommended TOC angle by sight method, whereas $44 \%$ obtained by ruler method. In addition, BL surface results show $63 \%$ by sight and $50 \%$ by ruler method.

The result of comparison in general between undergraduates and specialist as presented in Table 2 shows that $47 \%$ of the

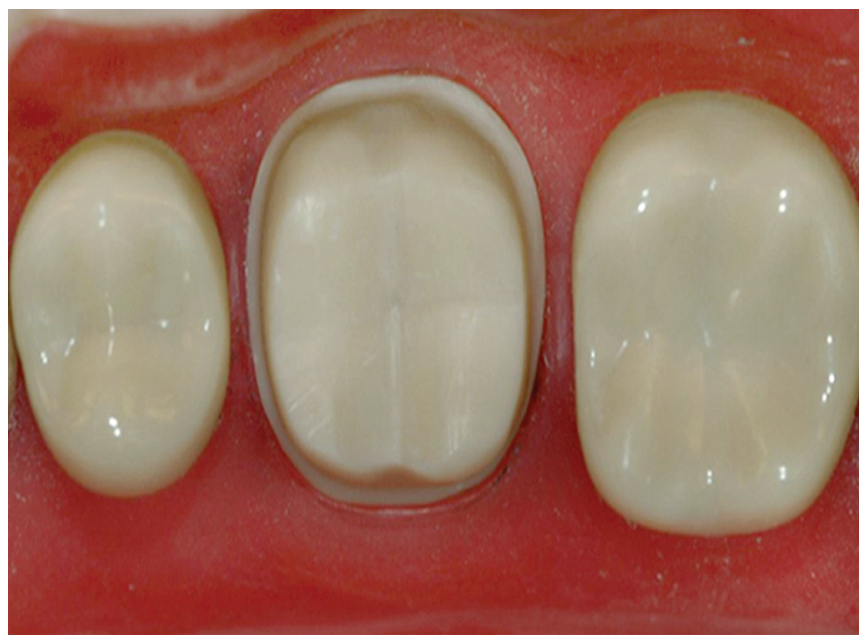

Fig. 1: Preparation of posterior tooth

Table 1: Percentage of observations that had a total occlusal convergence angle of $11^{\circ}$ to $20^{\circ}$

\begin{tabular}{lllll}
\hline & $\begin{array}{l}M D(n=300), \\
n(\%) \text { guessing }\end{array}$ & Ruler & $\begin{array}{l}B L(n=300), \\
n(\%) \text { guessing }\end{array}$ & Ruler \\
\hline $\begin{array}{l}\text { Dental students } \\
(n=100)\end{array}$ & 31 & 33 & 38 & 30 \\
$\begin{array}{l}\text { Interns }(n=100) \\
\begin{array}{l}\text { Specialists } \\
(n=100)\end{array}\end{array}$ & 49 & 28 & 59 & 26 \\
$p$ value & 0.012 & 44 & 63 & 50 \\
\hline
\end{tabular}

$\mathrm{MD}$, mesiodistal; $\mathrm{BL}$, buccolingual 
Table 2: Comparison of the percentage of recommended total occlusal convergence observations between undergraduates (D5 and intern) and specialists for both guessing and ruler readings

\begin{tabular}{lll}
\hline & $\begin{array}{l}\text { MD and } B L \\
\text { guessing }(n=600)\end{array}$ & $\begin{array}{l}\text { MD and } B L \\
\text { ruler }(n=600)\end{array}$ \\
\hline Undergraduates $(n=400)$ & 177 & 117 \\
Specialists $(n=200)$ & 112 & 94 \\
$p$ value & 0.007 & $<0.0001$ \\
\hline
\end{tabular}

$\mathrm{MD}$, mesiodistal; $\mathrm{BL}$, buccolingual

Table 3: Comparing the accuracy of total occlusal convergence angle based on guessing and ruler observation that match the digital reading

\begin{tabular}{lll}
\hline & $\begin{array}{l}\text { MD and BL guessing } \\
\text { reading that match } \\
\text { the digital reading } \\
(n=600)\end{array}$ & $\begin{array}{l}\text { MD and BL ruler } \\
\text { reading that match } \\
\text { the digital reading } \\
(n=600)\end{array}$ \\
\hline $\begin{array}{l}\text { Dental students } \\
(n=200)\end{array}$ & $12(6 \%)$ & $13(6.5 \%)$ \\
Interns $(n=200)$ & $23(11.5 \%)$ & $14(7 \%)$ \\
Specialists $(n=200)$ & $26(13 \%)$ & $19(9.5 \%)$ \\
Total & $61(10.17 \%)$ & $46(7.76 \%)$ \\
$p$ value & 0.051 & 0.482 \\
\hline
\end{tabular}

$\mathrm{MD}$, mesiodistal; $\mathrm{BL}$, buccolingual

specialist observation achieved the recommended TOC angle, while $29.25 \%$ was obtained by undergraduates.

Table 3 presents the result of comparison of the accuracy of using manual convergence angle ruler and guessing by sight to the digital snapshots done by the three groups (dental students, interns, and specialists); $10.17 \%$ of the reading by guessing method matched the digital snapshots, while the ruler reading matched it by $7.67 \%$.

The inference of the present study indicates that overall $47 \%$ of the specialist observation achieved the recommended TOC angle, while $29.25 \%$ obtained by undergraduates.

\section{Discussion}

One of the factors that affect the acceptance of a crown preparation is the TOC. As mentioned in the textbooks, achieving the idealistic TOC $\left(4^{\circ}\right.$ to $\left.14^{\circ}\right)$ in the oral cavity is nearly impossible. Goodacre et al. recommended in his systematic review that an angle from $10^{\circ}$ to $20^{\circ}$ can be accomplished in real-life situation and it is highly acceptable to achieve a better retention. ${ }^{9}$

The findings in this study showed that $30 \%$ of the prepared dies reached the idealistic angle recommended by textbooks, while $50 \%$ of the TOC of tooth preparations done in PNU dental clinics met the clinically recommended TOC $\left(10^{\circ}\right.$ to $\left.20^{\circ}\right)$, according to Goodacre et al. review. ${ }^{9}$

Specialist group showed maximum of their expertise in guessing by sight method compared with the ruler method; this could be because they do not have much knowledge or they have not practiced convergence angle ruler. On the contrary, $44 \%$ of the students observed properly $\left(10^{\circ}\right.$ to $\left.20^{\circ}\right)$ using sight, but around $71 \%$ did not observe properly $\left(10^{\circ}\right.$ to $\left.20^{\circ}\right)$ under ruler method, this led to an agreement that the students tend to give an overestimation readings. And the specialists can give a positive effect on their judgment or reading during their clinical crown preparations (Table 4).

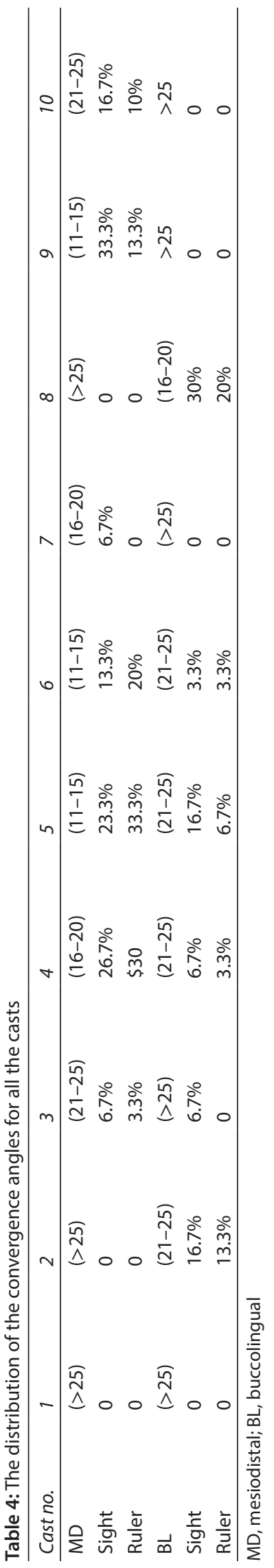


The retentive features mainly include biologic considerations. These affect the health of the oral tissues, which include avoidance of overcontouring, conservation of tooth structure, and harmonious occlusion. And mechanical considerations affect the durability and integrity of the restoration. ${ }^{15}$ It can be divided in to the following three categories: (1) providing retention form: it is the ability of the tooth preparation to resist the removal of the crown restoration along its path of insertion. (2) Providing resistance form: it is the ability of the preparation to resist the dislodgment of the restoration by forces directed obliquely or horizontally to the restoration. (3) Preventing deformation of the restoration: a restoration must have sufficient strength to prevent permanent deformation during function, so the restoration must have structural durability and marginal integrity. ${ }^{16}$

If the crown height is very less, then some of the measures can be taken to improve the retention such as placement of foundation restorations, alteration of tooth preparation design and placement of auxiliary retention and resistance form features, endodontic treatment and overlay removable partial dentures, orthodontic eruption, and surgical crown lengthening. ${ }^{17}$ The vestibular observation point shows a correctly tapered preparation to avoid undercuts.

In the present study, about $49 \%$ of the interns along with $31 \%$ of the students achieved the recommended TOC angle $\left(10^{\circ}\right.$ to $20^{\circ}$ ) for the respective MD surface by sight method, while $28 \%$ of the interns and $33 \%$ of the students obtained it by ruler method. These results are in contrast with Ow et al. ${ }^{18}$ who found $38 \%$ of their students preparing tapers greater than $20^{\circ}$. Our finding is also in contrast with Rafeek et al. ${ }^{19}$ who have achieved 62\% (MD) and $36 \%$ (BL) taper. Also El-Mubarak et al. ${ }^{20}$ showed $100 \%$ of their samples out of the ideal range (they prepared their first clinical case), and this could be due to the minimal preclinical experience of the students because of either lack of proper teaching aids or supporting staff, which had negative impact on the performance of the students.

Overall there was a marginally significant difference between ruler and sight guessing in their outcome comparing to the digital snapshots.

It is recommended to do more training on how to assess TOC angle. When in doubt underestimation is recommended to achieve a better outcome because majority of the literature and lab studies recommended some features of the preparation design. For example, restricting the preparation to enamel is considered to be a critical factor for a favorable bonding strength, thus more durable outcome. In addition, more accurate ways are available to asses TOC, such as AutoCad digital software.

The limitation of this study include (1) no equal distribution of the sampled TOC; (2) no proper training on how to use the ruler (first time users); (3) participants' availability and access to the digital software.

\section{ConcLusion}

Within the limitation, the present study concluded that specialists' observation was better in both ruler and sight guessing methods compared to the observations of dental students and interns. And further studies should be conducted with larger sample size to assess TOC.

\section{References}

1. Shillingburg HT, Hobo S, Whitsett LD, et al. Fundamentals of fixed prosthodontics. 3rd ed., Chi-cago: Quintessence; 1997.

2. Al-Moaleem M, Almakhloti E, Porwal A, et al. Evaluation of the degree of taper and convergence angle of full ceramo-metal crown preparations by different specialists centers at Assir region, Saudi Arabia. Saudi J Med Med Sci 2015;3(3):198-203. DOI: 10.4103/1658631X.161996.

3. Ghafoor R, Rahman M, Siddiqui A. Assessment of convergence angle of full-coverage porcelain fused to metal crowns in clinical practice. Indian J Dent Res 2012;23(2):241-246. DOI: 10.4103/0970-9290.100434.

4. Sato T, AlMutawaa N, Okada D, et al. A clinical study on abutment taper and height of full cast crown preparations. J Med Dent Sci 1998;45(3):205-210.

5. Aleisa K, AIDwairi Z, AlWazzan K, et al. Convergence angles of clinical tooth preparations achieved by dental students at King Saud University, Saudi Arabia. J Dent Educ 2012;77(9):1154-1158.

6. Ayad MF, Maghrabi AA, Rosenstiel SF. Assessment of convergence angles of tooth preparations for complete crowns among dental students. J Dent 2005;33(8):633-638. DOI: 10.1016/j.jdent.2004.12.008.

7. Dorriz H, Nokar S, Baghai Naini R, et al. The convergence angle of full-coverage crown preparations made by dental students. J Dent Tehran Uni Med Sci 2007;5(1):37-41.

8. Patel BP, Wildgoose GD, Winstanley BR. Comparison of convergence angles achieved in posterior teeth prepared for full veneer crowns. Eur J Prosthod Rest Dent 2005;13(2):100-104.

9. Goodacre CJ, Campagni WV, Aquilino SA. Tooth preparations for complete crowns: an art form based on scientific principles. J Prosthet Dent 2001;85(4):363-376. DOI: 10.1067/mpr.2001.114685.

10. Marghalani TY. Convergence angles of metal ceramic crowns prepared by dental students. J Prosthet Dent 2014;112(5):1250-1256. DOI: 10.1016/j.prosdent.2014.03.024.

11. AlAli K, AlWazzan K, AlAmri M, et al. Assessment of convergence angle of full veneer preparations carried out by practitioners with different levels of experience. Saudi Dent J 2009;21(1):37-44.

12. Kirov D, Kazakova S, Krastev D. Convergence angle of prepared Typodont teeth for full veneer crowns achieved by dental students. Int J Sci Res 2014;3:401-403.

13. Ghasemi S, Mireskandari P, Ghanizdah M, et al. Comparison of the convergence angle in full-crown abutment teeth prepared by the preclinical and senior students in Faculty of Dentistry Tabriz University. World J Dent 2017;8(2):77-80. DOI: 10.5005/jp-journals-10015-1416.

14. Makker R, Choukse V, Upadhyay M, et al. Assesment and comparison of convergence angle of tooth preparations for full-veneer crowns among practitioners with different levels of experience. Int J Prevent Clin Dent Res 2014;1(1):7-10.

15. Narula $S$, Punia V, Khandelwal $M$, et al. Retention in conventional fixed partial dentures: a review. J Clin Diagnos Res 2011;5(5):1128-1133.

16. Jayna M, Jayna A, Yadav B, et al. Clinical insight into tooth preparation: an update. Saint Int Dent J 2015;1(1):2-7. DOI: 10.4103/24543160.161793

17. Sharma A, Rahul GR, Poduval ST, et al. Short clinical crowns (SCC) - treatment considerations and techniques. J Clin Exp Dent 2012;4(4):e230-e236. DOI: 10.4317/jced.50556.

18. Ow C, Phuah D, Theocharopoulos. CAD evaluation of student first molar preparations. IADR Irish Division, Annual Scientific Meeting 2013, 15 Nov. (Abstract).

19. Rafeek RN, Smith WAJ, Seymour KG, et al. Samarawickrama, taper of full-veneer crown preparations by dental students at the University of the West Indies. Int J Prosthodont 2010;19(7):580-585. DOI: 10.1111/j.1532-849X.2010.00625.x.

20. El-MubarakN, Abu-BakrN, OmerO, et al. Assessment of undergraduate students' tooth preparation for full veneer cast restorations. Open Journal of Stomatology 2014;4(02):43-48. DOI: 10.4236/ ojst.2014.42008. 